\title{
NEM NO CONVENTO, NEM NO CABARÉ, NA IMPRENSA OPERÁRIA: A AMPLIAÇÃO DAS ESFERAS DISCURSIVAS DA MULHER TRABALHADORA NA REPÚBLICA VELHA*
}

\author{
Débora Luciene Porto Boenavides ${ }^{* *}$ \\ Universidade Federal do Rio Grande do Sul \\ Instituto de Letras \\ Porto Alegre, RS, Brasil
}

\begin{abstract}
Resumo: Neste artigo, investiga-se como a escrita da mulher trabalhadora na imprensa operária brasileira da República Velha (1889-1930) influenciou e refletiu a realidade da época. Para tanto, o estudo, ancorado na teoria dialógica do discurso, primeiramente contrapõe duas teses equivocadas advindas do imaginário das elites que, em suas representações, colocavam como lugar das mulheres trabalhadoras da época ora o convento, ora o cabaré, restringindo suas esferas discursivas e, com isso, as possibilidades de sua atuação linguística. Após, o artigo apresenta a relação da mulher trabalhadora com a imprensa operária como outra história de sua linguagem. Desta forma, demonstra-se que, a despeito de todas as tentativas de calar suas vozes, seja através do disciplinamento, da censura ou da estereotipação, os textos das trabalhadoras na imprensa operária mostram sua resistência e apontam os embates pelos quais ocorreu a ampliação de suas esferas discursivas na época.
\end{abstract}

Palavras-chave: Dialogismo. Imprensa. Mulher. Trabalho.

1 INTRODUÇÃO

O trabalho aqui desenvolvido tem como tema a ampliação das esferas discursivas das mulheres trabalhadoras no Brasil da República Velha, através de sua atuação, por meio da escrita ${ }^{2}$, na imprensa operária brasileira. Ao caracterizar nosso objeto de estudo, é importante, primeiramente, ressaltar que consideramos "jornais operários" aqueles que tinham como temática principal a questão da exploração da classe trabalhadora, sendo redigidos e lidos, assim, principalmente por trabalhadoras e por trabalhadores. Estes jornais eram, na maioria das vezes, vinculados a partidos, associações e sindicatos e guiados por ideais anarquistas e socialistas. Além disso, classificamos como trabalhadoras aquelas mulheres que, por não pertencerem à elite, não eram alheias ao trabalho, podendo este ocorrer em atividades industriais (operárias), agrícolas (agricultoras), comerciais (vendedoras, atendentes, etc.) ou educacionais (professoras).

\footnotetext{
* Este artigo é resultado parcial de pesquisa de mestrado em andamento, intitulada "Gênero, linguagem e trabalho: a escrita da mulher trabalhadora na imprensa operária brasileira da República Velha", sob a orientação da Profa. Dra. Florence Carboni.
}

\footnotetext{
** Mestranda em Letras/Sociolinguística no Programa de Pós-graduação em Letras. Bolsista CAPES. Email: professoradeboraporto@gmail.com.

2 Neste artigo, apesar de não menosprezarmos a atuação das mulheres enquanto leitoras dos jornais operários, nos limitaremos a analisar a produção dialógica dos textos por elas escritos.
} 
$\mathrm{O}$ artigo é fundamentado na teoria dialógica do discurso, que afirma que "o problema da relação recíproca entre a infra-estrutura e as superestruturas [...] pode justamente ser esclarecido, em larga escala, pelo estudo do material verbal", visto que o que nos interessa é compreender "como a realidade (a infra-estrutura) determina o signo, como o signo reflete e refrata a realidade em transformação" (BAKHTIN/VOLOCHÍNOV, 2010a, p. 42, grifos do autor). De tal modo, no presente trabalho nosso objetivo, de modo geral, é verificar e interpretar como a ampliação da esfera discursiva das mulheres trabalhadoras, através da sua atuação nos jornais operários, influenciou a realidade da época e refletiu/refratou a complexificação e a ampliação das relações trabalhistas brasileiras.

Temos como objetivos específicos analisar a presença de consciência de classe e de gênero nos textos publicados pelas mulheres trabalhadoras da República Velha e delinear o estilo desses textos, em comparação a textos de autoria masculina. Além disso, procuraremos compreender a motivação para o começo da escrita das mulheres nos jornais operários. Buscaremos perceber, assim, se estas preencheram espaços vazios ou se houve algum embate por estes espaços.

Para um recorte mais preciso, foram escolhidos dois jornais da imprensa operária do Rio de Janeiro: A Classe Operaria e Voz do povo ${ }^{3}$, por serem jornais de grande circulação e extensa tiragem, e pelo fato de o Rio de Janeiro, na época, ser a capital do Brasil e uma das cidades com maior número de habitantes, com maior desenvolvimento, com menor índice de analfabetismo e maior índice de industrialização (BRAZIL, 1922).

Desta forma, neste artigo, primeiramente discorreremos sobre o conceito de esfera discursiva a partir da teoria dialógica do discurso (TD), vinculando esta definição a outros conceitos importantes da TD (língua/linguagem, enunciado, gênero discursivo, estilo, carnavalização e polifonia). Após, buscaremos compreender a imprensa operária no contexto da República Velha. Assim, a partir dos conceitos da TD e da contextualização sócio-histórica, verificaremos os principais aspectos da imprensa operária da República Velha enquanto esfera discursiva possível para as mulheres trabalhadoras da época. Por último, verificaremos se os textos de autoria feminina na imprensa operária dos primeiros anos da industrialização brasileira são evidências para uma representação das mulheres trabalhadoras não estereotipada pelas classes dominantes.

\section{CONCEITO DE ESFERA DISCURSIVA NA TEORIA DIALÓGICA}

"Cada campo de criatividade ideológica tem seu próprio modo de orientação para a realidade e refrata a realidade à sua própria maneira. Cada campo dispõe de sua própria função no conjunto da vida social.” (BAKHTIN/VOLOCHÍNOV, 2009, p. 33). O conceito de esfera discursiva ${ }^{4}$ é de suma importância para a teoria dialógica do discurso. Primeiramente porque este conceito é recorrente nos textos escritos por Bakhtin e

\footnotetext{
${ }^{3}$ Muitos exemplares destes jornais podem ser encontrados na hemeroteca virtual da Biblioteca Nacional.

${ }^{4}$ Este conceito pode ser também chamado de campo discursivo, ou campo de atuação linguística, ou campo de criatividade ideológica, dependendo da tradução realizada ou da obra analisada.
} 
Volochínov. Ele está presente em A Palavra na Vida e na Poesia (VOLOCHÍNOV, 1926), em Marxismo e Filosofia da Linguagem (BAKHTIN/VOLOCHÍNOV, 19291930), em Problemas da poética de Dostoiéviski (BAKHTIN, 1929), em Que é a linguagem? (VOLOCHÍNOV, 1930), em A construção da enunciação (VOLOCHÍNOV, 1930), em Os gêneros do discurso (BAKHTIN, 1952-1953), em A Cultura Popular na Idade Média e no Renascimento (BAKHTIN, 1965) e em vários outros textos, visto que a linguagem e a literatura, principais objetos da teoria dialógica do discurso, são vistas por ela como indissociáveis das esferas da atividade humana, como indissociáveis da história. Em segundo lugar, porque o conceito de esfera discursiva vincula-se a outros conceitos importantes da TD. No presente artigo, analisaremos sua relação com as seguintes concepções: língua/linguagem, enunciado, gênero discursivo, estilo, carnavalização e polifonia. No entanto, acreditamos que, coerentemente, outros conceitos da $\mathrm{TD}^{5}$ possuem também relação com a concepção de esfera discursiva.

Iniciemos pela língua/linguagem. O conceito de esfera discursiva está na base da concepção bakhtiniana e volochinoviana de língua/linguagem. Desta forma, para a TD, o objeto de análise do linguista deve ser a língua como parte das práticas sociais, as quais devem servir para explicar como o sentido é construído pelos interlocutores nas relações sociais de poder e como o sentido constrói tais relações. Isto porque, de acordo com a TD, a língua não é um objeto sem significado ideológico, como são, "por exemplo, os fenômenos da natureza, os instrumentos de produção, os objetos da vida cotidiana, etc." (VOLOCHÍNOV, 2013, p. 191). Deste modo, de acordo com Volochínov em "A palavra e a sua função social", podemos usar, examinar e analisar os objetos sem significado ideológico e, ainda assim, o que observaremos não será mais que o próprio objeto, sua materialidade se manterá 6 . A língua, no entanto, é desde o início um fenômeno ideológico (VOLOCHÍNOV, 2013, p. 192), uma vez que ela existe apenas enquanto interação, não existe de forma independente dos seres humanos, como existem os objetos sem significado ideológico. Assim, o dado imediato, ou seja, a matéria da linguagem, não pode se restringir aos "elementos linguísticos (fonemas, morfemas e semelhantes). [...] $A$ linguagem não pode ser entendida dentro do sistema da natureza, mas somente dentro do sistema da história" (VOLOVHÍNOV, 2013, p. 261-262, grifo do autor). O dado imediato da linguagem deve ser, portanto, o enunciado.

A respeito das concepções de enunciado e de gênero discursivo, de acordo com a TD, devemos considerar que "todos os diversos campos da atividade humana estão ligados ao uso da linguagem"; desta forma, cada campo, cada esfera da atividade humana constrói suas próprias esferas discursivas e é construído por estas, nas quais são produzidos seus "tipos relativamente estáveis de enunciado, os quais denominamos de gêneros do discurso" (BAKHTIN, 2016, p.12). Assim,

\footnotetext{
${ }^{5}$ Podemos destacar, dentre estes, os conceitos de signo, de dialogismo, de heteroglossia, de tema e de significação.

${ }^{6}$ Volochínov aponta, em Marxismo e Filosofia da Linguagem (2017, p. 92), que "qualquer objeto da natureza, da tecnologia ou de consumo pode se tornar um signo", adquirindo "uma significação que ultrapassa os limites da sua existência particular". Deste modo, os objetos físicos podem ser ideologizados, existindo em sua materialidade e, ao mesmo tempo, refletindo e refratando uma outra realidade, a realidade dos signos.
} 
a riqueza e a diversidade dos gêneros do discurso são infinitas porque são inesgotáveis as possibilidades da multifacetada atividade humana e porque em cada campo dessa atividade vem sendo elaborado todo um repertório de gêneros do discurso, que cresce e se diferencia à medida que tal campo se desenvolve e ganha complexidade. (BAKHTIN, 2016, p.12).

Como apontamos acima, a concepção de estilo na TD também pode ser relacionada ao conceito de esfera discursiva. Assim, de acordo com Bakhtin, “'O estilo é o homem”; e nós podemos dizer, o estilo são pelo menos dois homens, ou mais exatamente, é o homem e seu grupo social na pessoa de seu representante ativo - o ouvinte, que é o participante permanente do discurso interno e externo do homem." (BAKHTIN, 2011, p. 178).

O grupo social apontado por Bakhtin em tal trecho são os participantes de determinado campo da atividade humana, são os interlocutores de determinada esfera discursiva, uma vez que, para a TD, o estilo "está indissoluvelmente ligado ao enunciado e às formas típicas de enunciados, ou seja, aos gêneros do discurso" (BAKHTIN, 2016, p. 17). Desta forma, Bakhtin mostra que o gênero, o tom e o estilo do enunciado são determinados pela esfera discursiva, por "quem fala e a quem se fala" em determinada esfera. Assim,

\begin{abstract}
Em cada época, em cada círculo social, em cada micromundo familiar, de amigos e conhecidos, de colegas, em que o homem cresce e vive, sempre existem enunciados investidos de autoridade que dão o tom, como obras de arte, ciência, jornalismo político, nas quais as pessoas se baseiam, as quais elas citam, imitam, seguem. Em cada época e em todos os campos da vida e da atividade, existem determinadas tradições, expressas e conservadas em vestes verbalizadas: em obras, enunciados, sentenças, etc. Sempre existem essas ou aquelas ideias determinantes dos "senhores do pensamento" de uma época verbalmente expressas, algumas tarefas fundamentais, lemas, etc. (BAKHTIN, 2010c, p. 294)
\end{abstract}

É possível dizer que a TD, ao apontar uma hierarquia discursiva, defende uma filosofia marxista da linguagem, em que os elementos da vida material são incontornáveis para se pensar as práticas linguísticas.

Ao mesmo tempo em que aponta a hierarquia discursiva no interior de determinadas esferas, a TD busca, na história, na linguagem e na literatura, esferas discursivas em que tal hierarquização não esteve presente. E assim surgem os conceitos de carnavalização e de polifonia.

A respeito da carnavalização, enquanto transposição, para a literatura, da linguagem das festas populares carnavalescas, acreditamos ser uma concepção que se refere a uma esfera discursiva não hierarquizada, uma vez que o carnaval "era o triunfo de uma espécie de liberação temporária da verdade dominante e do regime vigente, de abolição provisória de todas as relações hierárquicas, privilégios, regras e tabus" (BAKHTIN, 2010b, p. 8). Assim,

\footnotetext{
essa eliminação provisória, ao mesmo tempo ideal e efetiva, das relações hierárquicas entre os indivíduos, criava na praça pública um tipo particular de comunicação, inconcebível e situações normais. Elaboravam-se formas especiais de vocabulário e de gesto da praça pública, francas e sem restrições, que aboliam toda a distância entre os indivíduos em comunicação, liberados das normas correntes da etiqueta e da decência. (BAKHTIN, 2010b, p. 9)
} 
Sobre a polifonia, no entanto, é possível dizer que consiste em uma esfera discursiva não hierarquizada assimilada pelo gênero, a qual aparece no interior do romance polifônico. De acordo com Bakhtin, neste novo gênero literário, criado por Dostoievski, todas as vozes são equipolentes, os personagens principais são "não apenas objetos do discurso do autor mas os próprios sujeitos desse discurso." (BAKHTIN, 2002, p. 4).

Por último, entendemos que o conceito de esfera discursiva é essencial para a teoria dialógica do discurso por ser no interior das esferas que a luta de classes se manifesta. Assim, defendemos que, ao exaltar a possibilidade de equipolência das vozes do discurso literário, ao verificar a existência de uma esfera discursiva na qual as hierarquias não existiam, ao mostrar o caráter revolucionário da carnavalização, que "precede e prepara sempre as grandes transformações" (BAKHTIN, 2010b, p. 43), a TD segue na sua defesa por uma teoria marxista da linguagem, na qual um dos objetivos finais seria eliminação das contradições sociais nas esferas da vida humana, a qual acarretaria o fim das hierarquias, o fim das classes sociais também nas práticas discursivas.

\section{ESFERAS DISCURSIVAS DAS MULHERES TRABALHADORAS BRASILEIRAS NA REPÚBLICA VELHA: O CONVENTO, O CABARÉ E A IMPRENSA OPERÁRIA}

Os anos que constituem a época da chamada "República Velha" (1889-1930) foram marcados por mudanças econômicas e sociais no Brasil. Dentre essas mudanças, salientam-se as consequências da abolição da escravatura (em 1888), a Proclamação da República (em 1889) e o início do processo de industrialização, como nos mostra Giroletti (2002), a partir da segunda metade do século XIX.

Desta forma, a abolição da escravatura e o início do processo de industrialização vieram acompanhados por novas relações de trabalho. Já o processo de imigração assistida de europeus para a substituição de mão de obra escravizada para a assalariada e para o "embranquecimento" da população ${ }^{7}$ veio acompanhado dos ideais anarquistas e socialistas trazidos pelos imigrantes (GIANNOTTI, 2007, p. 62-76), juntamente com as suas línguas europeias (CARBONI et al., 2017, p. 11). Assim, se o Brasil da época teve mudanças significativas em sua infraestrutura (processos de produção e relações de trabalho), certamente estas mudanças causaram impacto em sua superestrutura (linguagem, discursos, ideologias).

É importante destacar que a força de trabalho feminina constituiu um importante elemento neste processo de substituição de mão de obra escravizada para assalariada, sendo expressivo o número de mulheres que trabalhava nas fábricas brasileiras nas primeiras décadas da industrialização. Saffioti (1981, p. 21-22) assinala que no Brasil, "em 1872, quase a totalidade dos trabalhadores do setor industrial eram mulheres" e que, em 1920, "as mulheres contribuíam com $65,1 \%$ dos contingentes humanos empregados na indústria têxtil e com 69,7\% da mão-de-obra do setor de confecções". Além disso,

\footnotetext{
${ }^{7} \mathrm{O}$ processo de imigração assistida de europeus ocorreu de forma desigual pelas regiões do país, tendo sido iniciado por D. Pedro II (adepto de teorias raciais) antes mesmo da proclamação da República e do fim da escravidão, e acelerado devido ao fim do modo de produção escravista (CARBONI, 2002, p. 121-124). 
destacamos o alto número de mulheres empregadas em serviço doméstico. Como aponta Chalhoub (2001, p. 204), "a tabela de profissões do censo do Distrito Federal indica que, do total de 117.904 pessoas que se declararam empregadas em serviço doméstico, 94.730 eram mulheres".

Apesar de sua forte atuação no mercado de trabalho, sabemos pouco sobre as trabalhadoras do início da industrialização brasileira, problema que é asseverado pelo fato de contarmos com documentos vários, com representações diversas da mulher trabalhadora (RAGO, 2012, p. 579). A maioria dos documentos normalmente analisada em estudos sobre a época, no entanto, por ter sido escrita por médicos higienistas, autoridades públicas, policiais, industriais ou militantes anarquistas ou socialistas, nos fornece a construção masculina ou burguesa da identidade das mulheres trabalhadoras, e não "sua própria percepção de sua condição social, sexual e individual." (RAGO, 2012, p. 579).

Desta forma, a representação dominante da mulher trabalhadora foi construída em dois polos. O primeiro, o da mulher santificada, a mulher do convento, forma como eram chamadas as hospedagens nas quais ficavam as jovens que vinham do interior para trabalhar nas fábricas dos centros urbanizados, a fim de manterem sua honra ${ }^{8}$. O segundo polo dessa representação é o da mulher do cabaré, demonizada por precisar percorrer sozinha as ruas para trabalhar e por possuir relações menos desiguais com os homens, visto que poderia prover seu próprio sustento 9 .

Por termos uma representação da mulher trabalhadora da época ora disciplinada pelo convento, ora "desvirtuada" pelo cabaré, acabamos por não buscar seus próprios discursos. Isso porque tanto o convento quanto o cabaré, não apenas enquanto espaços físicos, mas também enquanto esferas discursivas, têm os discursos neles produzidos inibidos, ocultados e restringidos, de forma que esses normalmente não permanecem no tempo, não entram para a história.

Apesar da tentativa de ocultamento dos discursos da mulher trabalhadora através de sua representação distorcida e do disciplinamento imposto à sua resistência, uma outra relação semântico-valorativa nos aparece, quando a procuramos nos jornais e nas revistas da época. Assim, na fotografia extraída da prestigiada revista paulistana A Cigarra do dia 26 de julho de 1917 (Figura 1), a qual, em sua edição número 71, noticiou a Greve Geral de 1917, vemos mulheres protestando em praça pública. Abaixo da fotografia, a legenda "Bandos de grêvistas, na maioria de mulheres operarias de varias fabricas desta capital, dirigindo-se ao largo do Palacio, a fim de conferenciar com o sr. secretário da Justiça e Segurança Pública, a quem pediram providencias contra o despropositado aumento dos gêneros de primeira necessidade". Se estas mulheres reivindicavam na esfera pública soluções para suas necessidades, se estas mulheres participavam de conferências na esfera política, há, com certeza, um descompasso entre o que se conta sobre elas e o modo como seus discursos afetaram e interpretaram sua própria realidade.

\footnotetext{
${ }^{8}$ Para um maior aprofundamento do tema, ver Giroletti (2002).

${ }^{9}$ Sobre a mulher demonizada, ver Chalhoub (2001) e Rago (2014).
} 
Figura 1 - Mulheres trabalhadoras reivindicam soluções para suas necessidades na Greve Geral de 1917

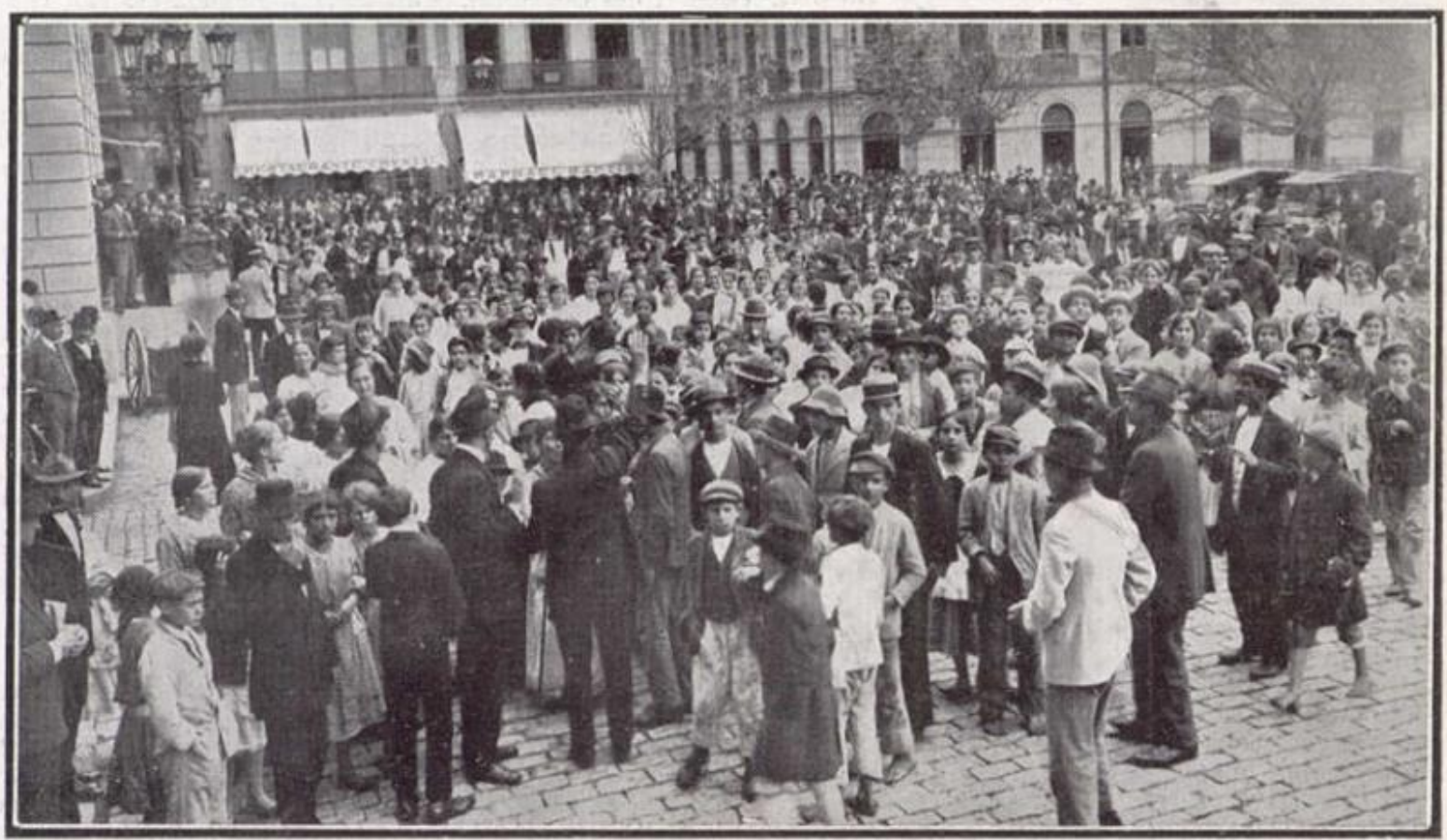

Bandus de grévisfas, na maioria mulheres operarias em varias fabricas desta copital. dirigindo-se ao largo do Palacio ofim de conferenciar com o sr. secreforio do Justiça e Segurança Publica, a quem pediram providencias contra o despropositado augmento dos generos de primeira necessidade.

Fonte: Revista "A Cigarra"10.

Todavia, uma fonte importante para conhecermos as lutas das mulheres trabalhadoras através de seus próprios discursos são os jornais operários da época. Por sua vez, a imprensa operária também sofreu ocultamento, sendo as estratégias para silenciá-la muito semelhantes àquelas às quais as mulheres trabalhadoras foram submetidas: a censura de seus textos e o ocultamento de uma classe trabalhadora capaz de escrever para estes jornais e capaz de constituir um público leitor destes, realizada por meio da estereotipação, do discurso dominante, que representava uma classe trabalhadora totalmente analfabeta.

Nas subseções que seguem, procuraremos, assim, destacar os principais aspectos da imprensa operária enquanto esfera discursiva das mulheres trabalhadoras. Desta forma, buscaremos caracterizar seus interlocutores, seus papéis sociais, seus enunciados recorrentes e seu estilo e, ao mesmo tempo, procuraremos interpretar e explicar como a atuação da mulher nesta nova esfera discursiva pode ter influenciado sua linguagem.

\footnotetext{
${ }^{10}$ Várias edições desta revista estão disponíveis digitalmente no site do Arquivo Público do Estado de São Paulo.
}

BOENAVIDES, Débora Luciene Porto. Nem no convento, nem no cabaré, na imprensa operária: a ampliação das esferas discursivas da mulher trabalhadora na República Velha. Linguagem em (Dis)curso - LemD, Tubarão, SC, v. 17, n. 3, p. 297-313, set./dez. 2017. 
Em Fábrica: convento e disciplina, Domingos Giroletti transcreve o seguinte diálogo do romance Fazenda da Ponte (1968), escrito por Maria Helena Ribeiro, uma exoperária mineira:

-... Aquela casa comprida, à direita, que foi recentemente construída, é o Convento.

- Convento?

- Sim senhora. Mas não passa de um pensionato para moças. E talvez pelo fato de viverem ali as moças algum tanto enclausuradas, apelidaram à calma vivenda de Convento. (RIBEIRO apud GIROLETTI, 2002, p. 237)

Neste trecho, a autora traz sua visão sobre os chamados "conventos" de Minas Gerais, os quais, conforme Giroletti (2002, p. 238), "foram organizados pelos empresários para abrigar moças reunidas com a finalidade de trabalhar nas fábricas. Era uma forma barata de recrutar mão de obra necessária porque evitava, em primeiro lugar, a imobilização de capital na construção de casas para operários”.

Enclausurar as mulheres trabalhadoras não era apenas uma forma de manter sua honra, havia o nexo monetário envolvido nesta prática. Além dos baixos custos que os empresários tinham com os conventos, cabe destacar que essas residências também constituíam uma das formas de disciplina imposta às mulheres trabalhadoras. Enclausuradas nesses pensionatos, as moças seguiam as rotinas impostas por seus patrões, os quais, em troca de seu trabalho, lhes davam apenas o suficiente para sua subsistência (GIROLETTI, 2002). Questionamos, então, quais as práticas linguageiras possíveis para estas mulheres, das quais temos uma representação silenciosa, característica dos conventos.

A disciplina imposta às trabalhadoras e aos trabalhadores do Brasil da República Velha também é apontada por Margareth Rago, que nos mostra que "Contra as estratégias de enquadramento do proletariado ao modelo disciplinar imaginado pelos dominantes, a criatividade operária opõe inúmeras formas de resistência, surdas, difusas, organizadas ou não, mas permanentes, efetivadas no interior do espaço de produção." (RAGO, 2014, p. 44).

Deste modo, é possível depreender que gestos e discursos contra o disciplinamento eram produzidos nas esferas discursivas do trabalho fabril, de modo que as tentativas dos patrões de controlar as trabalhadoras e os trabalhadores restavam muitas vezes falhas.

Artur José Renda Vitorino mostra, em seu livro Máquinas e operários, que, no Brasil, a imprensa, desde o seu surgimento, foi usada para divulgar "uma produção doutrinária e opinativa" (2000, p. 15). Assim, mesmo que Portugal já fizesse uso da imprensa desde o século XV e já tivesse instituído a impressão tipográfica em suas colônias orientais desde o século XVI, no Brasil a primeira oficina tipográfica foi surgir apenas no século XVIII (no Rio de Janeiro, em 1747). No entanto, essa oficina foi fechada pela provisão, e todo o seu material foi apreendido logo que Portugal soube de sua existência. Foi, então, apenas com a "mudança do governo português para o Rio de Janeiro, em 1808, que se deu a instalação de uma imprensa para a publicação de atos 
oficiais" (VITORINO, 2000, p. 23-24). Toda e qualquer outra publicação, nesta época, precisava ser submetida à análise de conteúdo. Essa censura não se limitava aos textos escritos no Brasil: para importar livros de outros países era necessário também pedir autorização à autoridade imperial.

Apesar desse controle, nessa época, “jornais e folhetos circularam anonimamente na cidade do Rio de Janeiro e nos principais centros urbanos do país" (VITORINO, 2000, p. 26). Em nossa pesquisa nas hemerotecas, vimos que diversos jornais tinham suas edições descontinuadas devido a seu fechamento, como é o caso do jornal A Classe Operaria, criado em 1925 e fechado logo após sua primeira publicação, sendo reaberto em 1928 e tendo os seus períodos de clandestinidade, devido à censura e à repressão. Assim, é possível dizer que, desde seu surgimento, a imprensa brasileira, fosse ela operária ou não, teve seus momentos de liberdade e de censura, servindo, muitas vezes, à luta política, seja de forma oficial ou clandestina.

No entanto, mesmo com toda a censura existente na época, entre 1889 e 1930, existia uma variedade de formas associativas populares, as quais eram muitas vezes responsáveis pela edição e distribuição de jornais operários. Assim, "antes que o padrão estatal do sindicato único por categoria se impusesse, era bastante heterogêneo o quadro sindical e associativo dos trabalhadores no Brasil" (HARDMAN, 2003, versão Kindle, posição 345-346), o que fez com que a imprensa operária dessa época tivesse maior autonomia ideológica que no pós-1930. Pode-se, assim, concluir que a censura na República Velha buscava recriminar os discursos publicados nos jornais, impedindo-os de circular após sua escrita. Por outro lado, o padrão estatal do sindicato único por categoria buscava controlar as ideologias das trabalhadoras e dos trabalhadores, o que impedia já a produção de determinados tipos de discurso.

\subsection{O CABARÉ: OS ESTEREÓTIPOS DA CLASSE TRABALHADORA}

Embora o 'aproveitamento' ou a exploração da mão de obra feminina tenha ocorrido desde o início da colonização do Brasil, foi apenas com a industrialização que os debates acerca do trabalho feminino começaram a surgir publicamente. Assim, "A burguesia, os legisladores, os anarquistas e os socialistas, médicos, advogados, educadores, discutem uma série de questões até aí consideradas novas" (LOPES, 1985, p.11). Tais discussões a respeito do trabalho feminino, além de criarem uma representação imaginária sobre a mulher trabalhadora, tinham o intuito de colonizar as mulheres trabalhadoras e de impor "o modelo imaginário de família criado pela família burguesa." (RAGO, 2014, p. 86).

Chalhoub (2001) argumenta que as condições materiais da classe trabalhadora na cidade do Rio de Janeiro no início do século XX "levavam a tipos de relação homemmulher que se caracterizavam por uma maior simetria” (p. 227-228). Entre as condições que justificam esta tese estão a capacidade das mulheres trabalhadoras de gerar o próprio sustento e o sustento dos filhos e a característica solidária das redes criadas por trabalhadores para sua própria sobrevivência, nas quais as mulheres exerciam o importante papel de garantir sua continuidade. A maior simetria entre os gêneros permitia 
que as trabalhadoras da época rompessem seus relacionamentos amorosos facilmente, tendo em vista sua independência em relação aos homens. Tais rompimentos não eram bem-vistos pela classe dominante e, por consequência, pelos homens pobres, que além de apreenderem os estereótipos dominantes da dominação da mulher pelo homem, viam os rompimentos como "uma desarticulação de seu modo de vida" (CHALHOUB, 2001, p. 229), baseados nas redes solidárias construídas entre a classe trabalhadora.

Deste modo, apesar da simetria na relação entre homem-mulher indicada pelas condições materiais,

\begin{abstract}
A invasão do cenário urbano pelas mulheres, no entanto, não traduz um abrandamento das exigências morais, como atesta a permanência de antigos tabus como o da virgindade. Ao contrário, quanto mais ela escapa da esfera privada da vida doméstica, tanto mais a sociedade burguesa lança sobre os seus ombros o anátema do pecado, o sentimento de culpa diante do abandono do lar, dos filhos carentes, do marido extenuado pelas longas horas de trabalho. Todo um discurso moralista e filantrópico acena para ela, de vários pontos do social, com o perigo da prostituição e da perdição diante do menor deslize. (RAGO, 2014, p. 88-89).
\end{abstract}

Esse discurso moralista tinha a finalidade de limitar a liberdade das mulheres de circularem nos espaços públicos e de barrar uma maior simetria na relação entre homens e mulheres trabalhadores que se desenhava na época.

É construída assim, pelos homens trabalhadores, pelos médicos higienistas, pelos legisladores e pela burguesia, a figura da mulher pública, mulher selvagem, prostituta, que tem preguiça de trabalhar honestamente e por isso se entrega ao modo mais fácil de garantir sua sobrevivência, em oposição à figura "da mulher honesta, casada, boa mãe, laboriosa, fiel e dessexualizada" (RAGO, 2014, p. 122). Destacamos que tal estereotipação fez com que as mulheres da esfera pública fossem, assim, também no campo da linguagem, silenciadas por esta estratégia que desqualificava seus discursos.

Cabe destacar, no entanto, que o modelo de família imposto pela classe dominante e essa representação "desvirtuada" da mulher da esfera pública eram amplamente combatidos pelas mulheres que escreviam na imprensa operária. Maria Lacerda de Moura, já destacada em diversos estudos sobre a imprensa operária da época, por exemplo, em seu livro Han Ryner e o Amor Plural, de 1928, argumenta sobre o fato, mostrando o nexo entre a mulher prostituída, submetida ao cafetão, e a mulher casada, submetida ao marido:

\footnotetext{
E o homem continua a querer entravar-lhe os movimentos e, portanto, cercear-lhe o progresso. A mulher só tem direito de sair, de se locomover se vai trabalhar, ganhar dinheiro. Continua dando conta ao homem de todos os seus passos e até do seu salário. É outra espécie de exploração.

É o caftismo em família [...]. (MOURA apud RAGO, 2014, p. 135)
}

Surge, a partir da constatação da exploração sofrida pelas mulheres trabalhadoras, a defesa pela sua instrução como forma de resistência. No jornal operário $O$ Amigo do Povo de 17/01/1904, Matilde Magrassi defende a educação das mulheres trabalhadoras "a fim de melhorar um pouco vossa crítica situação" (MAGRASSI, apud RAGO, 2014, 
p. 131). A existência de textos como este, que se dirigem às mulheres trabalhadoras, nos faz questionar outro estereótipo da mulher trabalhadora, e da classe trabalhadora como um todo, criado pela classe dominante: a figura de uma classe analfabeta, incapaz de reivindicar seus direitos.

Desta forma, destacamos que, a partir da década de 1890, época que nos interessa no presente trabalho, houve uma modernização das tipografias brasileiras, que passaram a utilizar máquinas de impressão rotativa. Segundo Vitorino (2000), esta modernização foi necessária devido ao aumento do número de leitores, ocasionado, também, pelo início da venda avulsa de jornais nos centros urbanos brasileiros. Sobre o número de leitores destes jornais, parece existir uma lacuna entre os números publicados pelos censos da época, a respeito da alfabetização, e a tiragem e a variedade de jornais escritos em língua portuguesa e em língua estrangeira durante a República Velha.

De acordo com o recenseamento da cidade do Rio de Janeiro de 1906, dos seus 811.443 habitantes, 421.072 sabiam ler e escrever. Dos que sabiam ler e escrever, 160.131 eram mulheres. Assim, a taxa de analfabetismo da época ficava em 43,70\% entre os homens e 53,98\% entre as mulheres. Apesar destes altos índices, o próprio recenseamento de 1920 apontou o equívoco do censo de 1906: entre os números apontados, foram inseridas as crianças menores de 5 anos, que não deveriam estar nessa estatística, devido ao fato de não terem ainda idade escolar. Na figura 2, vemos as estatísticas do recenseamento de 1920, um pouco mais favoráveis.

Figura 2 - Recenseamento da cidade do Rio de Janeiro de 1906

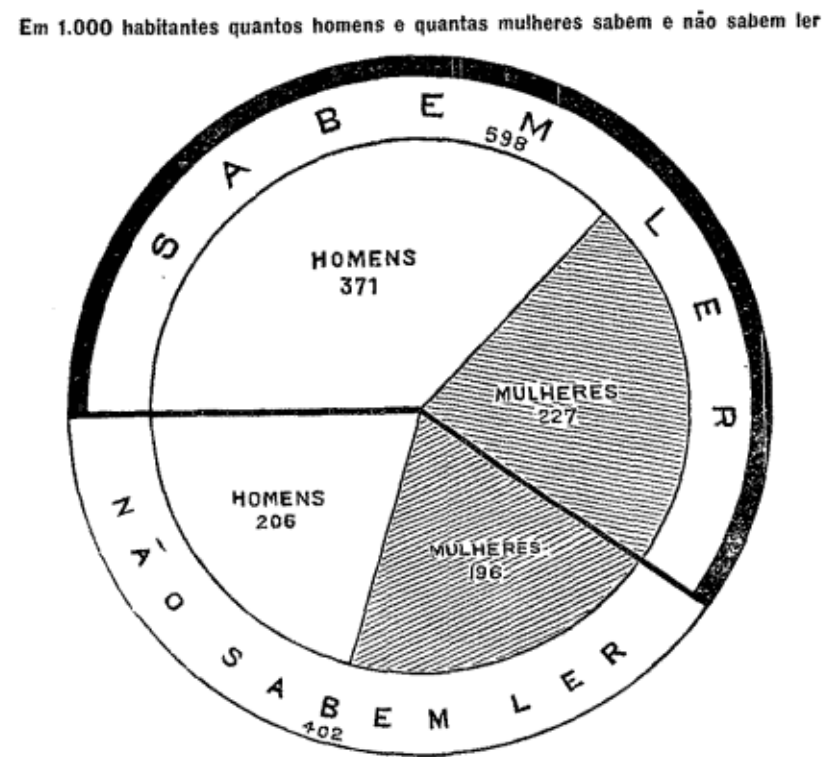

Fonte: Rio de Janeiro, 1907.

Apesar de um pouco maior, a porcentagem de mulheres alfabetizadas permanece pequena, e parece não coincidir com o que nos mostram os jornais operários da época, nos quais encontramos inúmeros textos redigidos por mulheres trabalhadoras $\mathrm{e}$ direcionados a elas. Heller (2006, p. 12) aponta que, embora o percentual de mulheres que sabia ler e escrever na época fosse pequeno, segundo o recenseamento de 1920, este 
número pode ter sido subestimado, "pois é muito provável que mulheres alfabetizadas não tenham sido recenseadas, seja por residirem em bairros de difícil acesso, seja por não estarem fora de suas residências, uma vez que poderiam ser trabalhadoras, seja por saberem apenas ler e não escrever." (HELLER, 2006, p.12).

Sobre o último argumento citado por Heller, o fato de parte das mulheres recenseadas poderem ter sido classificadas como analfabetas por saberem apenas ler $\mathrm{e}$ não escrever, destacamos que foram inseridas entre os não alfabetizados, pessoas que não sabiam ler 'ou' escrever. Desta forma, é possível dizer que, devido à sua metodologia, os recenseamentos contribuíram para a visão que temos hoje da classe trabalhadora da época: de iletrada. Acreditamos que tal estereotipação, assim como a feita com as mulheres que circulavam na esfera pública, contribuiu também para o silenciamento das trabalhadoras da época, afetando também os trabalhadores. Desta forma, destacamos o preconceito linguístico ao qual foi submetida a classe trabalhadora da época, que fez com que suas vozes soassem enfraquecidas nas esferas discursivas políticas. Podemos, através do nosso conhecimento geral, apontar que essa prática que se firmou nos primórdios das relações de trabalho livre no Brasil se manteve e continua sendo empregada como estratégia das classes dominantes para calar a classe trabalhadora.

\subsection{A RELAÇÃO ENTRE A MULHER TRABALHADORA E A IMPRENSA OPERÁRIA: UMA OUTRA HISTÓRIA DA LINGUAGEM}

Apesar de as mulheres não pertencentes à elite nunca terem sido alheias ao trabalho, somente com o início do processo de industrialização começamos a ter notícias mais consistentes das lutas (por melhores condições de vida e de trabalho) das mulheres trabalhadoras através de seus próprios discursos, por meio dos textos por elas escritos na imprensa operária, visto que os jornais constituíam um importante meio para a troca de informação e de ideias entre classes letradas da época (HAHNER, 1981, p.51). Assim, por mais que as mulheres trabalhadoras já tivessem (por vezes) reivindicado seus direitos em outras esferas, não havia, antes do surgimento da imprensa, forma pública de fazer com que seus discursos permanecessem no tempo.

Podemos ilustrar essa afirmação com o texto a seguir, escrito pelas charuteiras de $\mathrm{S}$. Félix e assinado coletivamente, o que nos parece ser indício de uma consciência de classe das mulheres trabalhadoras. O manifesto foi veiculado no jornal A Classe Operaria $^{11}$ de 30 de maio de 1925 . Nele, as operárias apontam como eram exploradas, reivindicando melhores condições econômicas, políticas e higiênicas:

[...] Levamos ao conhecimento do proletariado industrial e agrícola os horrores que soffremos. Somos tratadas como seres inferiores. [...]

Os que, nas grandes cidades, nas casas elegantes, fumam os charutos finos do S. Félix, mal sabem a exploração innominavel a que somos submetidas.

\footnotetext{
11 Jornal fundado pelo Partido Comunista Brasileiro. É importante destacar que a transcrição dos textos enviados através de cartas, no período estudado, era feita por Laura Brandão, esposa de Otávio Brandão Rego, um dos fundadores do jornal. Pressupomos que, nessa transcrição, adaptações linguísticas podem ter sido feitas nos textos.
} 
Nossas aspirações são as seguintes:
(A) Economicas:
$1^{\text {a }}$ - Salario fixo de $\$ 5$ diarios, por 250 charutos a pau ou 100 charutos a mão; [... $6^{\text {a }}$ - Licença de 15 dias para as companheiras no parto e pagamento integral.
(B) Hygienicas:
$7^{\mathrm{a}}$ - Agua pura e copos;
$8^{\text {a }}$ - Bancos especiais para as companheiras gravidas.
(C) Politicas:
9 - Direito de livre associação;
$10^{\mathrm{a}}$ - Não sermos despedidas quando commemorarmos o primeiro de maio.
(CHARUTEIRAS DE S. FÉLIX, 1925)

A consciência de gênero e de classe também pode ser verificada em texto publicado no jornal Voz do Povo de 07/02/1920, pelo "Grupo Feminino de Estudos Sociaes" do Rio de Janeiro. No texto, intitulado "Um manifesto à mulher brasileira", é feita uma chamada para que mulheres trabalhadoras participassem do grupo, rechaçando a prostituição a que eram submetidas as mulheres trabalhadoras (o que pode indicar uma reprodução do discurso dominante, que, como mostramos, demonizava a mulher pública, a mulher do cabaré) e exaltando a emancipação das mulheres, independentemente de sua profissão:

\footnotetext{
O Grupo Feminino de Estudos Sociaes, fundado nesta capital em 22 de janeiro de 1920, propõem-se a agremiar todas as mulheres emancipadas do Brazil, afim de combater systematica e eficazmente a escravisação clerical, a escravisação economica, a escravisação moral e a escravisação jurídica que asphyxiam, degradam e aviltam o sexo feminino. [...]

O Grupo aceitará como sócias todas as mulheres dignas, sem differenças de raça, nacionalidade, crença ou profissão [...].

Companheiras:

Urge elevar, engrandecer, dignificar o nosso sexo, liberta-lo mental e socialmente. Precisamos de combater a escravidão em que sempre nos prenderam, e que tem sido em todos os tempos a causa única dos desvios da humanidade. [...]

Professoras, funccionarias, costureiras, floristas, operarias em fábricas e "ateliers", trabalhadoras em artes domésticas: vinde, vinde até nós que sereis jubilosa e fraternalmente acolhidas. (Grupo Feminino de Estudos Sociaes, 1920).
}

Além da presença de uma consciência coletiva das mulheres trabalhadoras da época, podemos afirmar que, a despeito de todas as tentativas de calá-las, seja através de disciplinamento, da censura ou da estereotipação, seus textos na imprensa operária mostram sua resistência, como vemos no texto de Hermelinda Borges, no jornal A Classe Operária de 25/08/1928. Neste texto, a autora, operária pespontadeira, defende a importância de as mulheres se envolverem na política, mesmo ainda não tendo direito ao voto:

É chegado o momento de auxiliarmos os nossos companheiros nas lutas eleitoraes que se approximam.

A victoria dos nossos candidatos proletarios depende de uma votação cerrada em seus nomes, e para conseguirmos este objectivo muita propaganda e agitação se torna preciso. 
A nós, mulheres proletarias, grande tarefa compete. Si ainda não dispomos do direito do voto, podemos, no entanto, agir com dedicação e atividade junto as mais largas massas operarias, incentivando-as a luta eleitoral, interessando-as na sua politica da classe pobre contra a classe rica. (BORGES, 1928).

A imprensa operária, no entanto, não se constituía como esfera discursiva igualitária, apesar de ser uma esfera discursiva na qual trabalhadoras e trabalhadores expunham suas condições de trabalho e reivindicavam seus direitos. Como já apontamos, o movimento operário, liderado por homens trabalhadores, "atuou no sentido de fortalecer a intenção disciplinadora de deslocamento da mulher da esfera pública do trabalho e da vida social para o espaço privado do lar" (RAGO, 2014, p. 89). Neste sentido, não haveria motivos para que a escrita da mulher da imprensa operária se desse sem embate.

Em texto publicado no jornal Voz do Povo de 10/02/1920, por exemplo, operários que "se orgulhavam em ser propagandistas de sua associação de classe" anunciam, em texto não assinado, uma greve na fábrica de tecidos em que trabalhavam. O motivo: após uma greve anterior, tinham conseguido a transferência de uma operária da fábrica. No entanto, a operária conseguiu retornar, sob a proteção do gerente da fábrica, que demitiu os homens que haviam pedido sua transferência, alegando não precisar da mão de obra desses, devido à falta de matéria prima para a produção de tecidos. No recorte abaixo, é possível perceber um discurso bastante machista, no qual os operários justificam sua ação (de fazer greve), dizendo que "reagiram como homens" e apresentam a operária inimiga como "indigna".

[...] Os operários que hontem tinham feito com que os patrões assignassem um acordo que entre outras concessões estipulara o afastamento da secção d'essa operaria, que é indigna de viver no meio dos trabalhadores, reagiram como homens e imediatamente abandonaram o serviço e só o retomarão quando for cumprido á risca o acordo que esses sur, assignaram com a União, isto é, que essa mulher seja afastada da secção de teares e que sejam readmitidos seus companheiros. (A GREVE NA FABRICA DE TECIDOS SANTO ANTONIO, 1920, grifo nosso).

Ao comparar os textos de autoria feminina com os de autoria masculina, é possível verificar a presença de um estilo mais argumentativo nos recortes de autoria feminina e de um estilo mais narrativo no recorte de autoria masculina. Até mesmo em textos com a mesma função, de reivindicar, são utilizados estilos diferentes para atingir o objetivo pretendido. Desta forma, enquanto as operárias charuteiras de S. Félix expunham suas aspirações, explicando seus motivos, os operários da Fábrica de Tecidos Santo Antonio relatavam que haviam paralisado seu serviço e só retornariam se o acordo feito entre eles e o seu patrão fosse cumprido. Ainda, enquanto nos textos assinados por mulheres é utilizada a primeira pessoa do plural, o texto que trata dos homens nem mesmo é assinado, sendo utilizada a terceira pessoa do plural, de modo impessoal. Podemos atribuir o modo impessoal e a autoria não marcada à valorização do masculino na linguagem, uma vez que uma das características do Português Brasileiro é ter como "gênero neutro" o gênero masculino ("o homem").

Além disso, defendemos que a territorialização de seus discursos na imprensa operária, ou seja, a conquista desta esfera discursiva pelas mulheres, a expansão de seu 
campo de atuação linguística, não se deu de forma horizontal, através da ocupação de um espaço vazio, ou cedido pelos homens. Nos próprios jornais, como vimos, é possível encontrar provas de que os homens utilizavam a imprensa operária inclusive para questionar a presença da mulher no mercado de trabalho e para divulgar tentativas de expulsá-las desse espaço. Nos termos da TD, nem sempre havia equipolência entre as vozes femininas e masculinas, sendo as primeiras, muitas vezes, apenas objeto dos discursos dos homens, e não sujeitos de seus próprios discursos. Assim, é possível verificar que a territorialização discursiva das mulheres na imprensa operária deu-se através de embates, sendo preciso que as mulheres ultrapassassem não apenas as fronteiras impostas pelas classes dominantes, mas também as fronteiras impostas pelos homens trabalhadores, já que estes consideravam que as mulheres eram uma ameaça à valorização da força de trabalho masculina (RAGO, 2014, p. 91).

\section{CONSIDERAÇÕES FINAIS}

Verificamos neste trabalho que a escrita das mulheres na imprensa operária da República Velha influenciou a realidade da época, de forma que as classes dominantes e os homens trabalhadores, atentos à conquista do espaço público pelas mulheres, buscaram estratégias para fazer com que elas voltassem à esfera privada, como forma de silenciálas.

Além disso, vimos que a equipolência de vozes, pregada pelos ideais anarquistas e socialistas, não era regra no interior da imprensa operária enquanto esfera discursiva da época. No entanto, as mulheres trabalhadoras também elaboraram suas próprias estratégias para que seus discursos reverberassem através dessa esfera. Estas estratégias serão abordadas em um próximo artigo, no qual analisaremos os enunciados recorrentes nos textos escritos pelas mulheres trabalhadoras na imprensa operária da República Velha.

\section{REFERÊNCIAS}

A GREVE NA FABRICA DE TECIDOS SANTO ANTONIO. Voz do Povo: órgão da Federação dos Trabalhadores do Rio de Janeiro e do Proletariado em geral. Rio de Janeiro, 10 fev. 1920. Disponível em: <http://memoria.bn.br/pdf/720003/per720003_1920_00005.pdf>. Acesso em: 4 jan. 2017.

BAKHTIN, M. Problemas da poética de Dostoiévski. Tradução de Paulo Bezerra. 3. ed. Rio de Janeiro: Forense Universitária, 2002.

(V. N. Volochínov) Marxismo e filosofia da linguagem: problemas fundamentais do método sociológico da linguagem. Prefácio Roman Jakobson; Apresentação de Marina Yaguello. 14. ed. São Paulo: Hucitec, 2010a.

A cultura popular na Idade Média e no Renascimento: o contexto de François Rabelais. São Paulo: Hucitec, 2010b.

Estética da criação verbal. Tradução de Maria Ermantina Galvão Gomes Pereira. 5. ed. São Paulo: Martins Fontes, 2010c.

A Palavra na vida e na poesia. Introdução aos problemas da poética sociológica. In: BAKHTIN, Mikhail. Palavra própria e palavra outra na sintaxe da enunciação. São Carlos: Pedro e João Editores, 2011. 
Os Gêneros do discurso. Organização, tradução e notas de Paulo Bezerra; Notas da edição russa de Serguei Botcharov. São Paulo: Editora 34, 2016.

BORGES, H. Mulheres trabalhadoras do Brasil, alerta! A Classe Operaria: jornal de trabalhadores, feito por trabalhadores. Rio de Janeiro, 25 ago. 1928. Disponível em: <http://memoria.bn.br/pdf/086569/per086569_1928_00018.pdf>. Acesso em: 24 out. 2016.

BRAZIL. Ministerio da Agricultura, Industria e Commercio. Directoria Geral de Estatistica. Recenseamento do Brazil: realizado em 1 de Setembro de 1920. Rio de Janeiro: Typ. da Estatística, 1922. Disponível em: <http://biblioteca.ibge.gov.br/visualizacao/livros/liv6478.pdf>. Acesso em: 8 set. 2017.

CARBONI, F. "Eppur si parlano!" Étude diachronique d'un cas de contact linguistique dans le Rio Grande do Sul. Passo Fundo: UPF, 2002.

; BOENAVIDES, D. L. P.; BARILI, C.; MELEU, S. M. O plurilinguismo na história do Brasil: considerações exploratórias. Organon, v. 32, n. 62 "Plurilinguismo na educação e na sociedade", jan./jul. 2017. Disponível em: <http://seer.ufrgs.br/index.php/organon/article/view/72315>. Acesso em: 7 set. 2017.

CHALHOUB, S. Trabalho, lar e botequim. O cotidiano dos trabalhadores no Rio de Janeiro da belle époque. 2. ed. Campinas, SP: Editora UNICAMP, 2001.

CHARUTEIRAS DE S. FÉLIX. As operarias charuteiras da Bahia appellam para "A Classe Operaria”. A Classe Operaria: jornal de trabalhadores, feito por trabalhadores. Rio de Janeiro, 30 maio 1925.

Disponível em: <http://memoria.bn.br/pdf/086569/per086569_1925_00005.pdf>. Acesso em: 27 jul. 2016.

GIANNOTTI, V. História das lutas dos trabalhadores no Brasil. Rio de Janeiro: Mauad X, 2007.

GIROLETTI, D. Fábrica: convento e disciplina. Brasília: Editora da Universidade de Brasília, 2002.

GRUPO FEMININO DE ESTUDOS SOCIAES. Um manifesto à mulher brasileira. Voz do Povo: órgão da Federação dos Trabalhadores do Rio de Janeiro e do Proletariado em geral. Rio de Janeiro, 7 fev.1920. Disponível em: <http://memoria.bn.br/pdf/720003/per720003_1920_00003.pdf>. Acesso em: 4 jan. 2017. HAHNER, J. A mulher brasileira e suas lutas sociais e políticas: 1850-1937. São Paulo: Editora Brasiliense, 1981.

HARDMAN, F. F. Nem pátria, nem patrão: Memória operária, cultura e literatura no Brasil. São Paulo: UNESP, 2003. Edição Kindle.

HELLER, B. Da pena à prensa: mulheres e leitura no Brasil (1890-1920). São Paulo: Porto de Idéias, 2006.

LOPES, E. da S. Fragmentos de Mulher (Dimensões da trabalhadora (1900/1922)). 1985. $248 f$.

Dissertação (Mestrado em História), Instituto de Filosofia e Ciências Humanas, Universidade Estadual de Campinas, Campinas, 1985.

PERROT, M. As Mulheres, o poder, a história. In: PERROT, M. Os excluídos da história: operários, mulheres e prisioneiros. Tradução de Denise Bootmann. Rio de Janeiro: Paz e Terra, 1988.

RAGO, M. Trabalho feminino e sexualidade. In: DEL PRIORE, M. (Org.). História das mulheres no Brasil. 10. ed., 1. reimpr. São Paulo: Contexto, 2012. p. 579-606. Terra, 2014

Do cabaré ao lar: a utopia da cidade disciplinar (Brasil 1890-1930). 4. ed. São Paulo: Paz e

RIO DE JANEIRO. Recenseamento da cidade do Rio de Janeiro de 1906. Rio de Janeiro: Officina de Estatistica, 1907. Disponível em: <http://biblioteca.ibge.gov.br/visualizacao/livros/liv49678.pdf〉. Acesso em: 10 dez. 2016.

SAFFIOTI, H. A mulher na sociedade de classes: mitos e realidade. Rio de Janeiro: Rocco, 1979.

Do artesanal ao industrial: a exploração da mulher. São Paulo: Hucitec, 1981.

VITORINO, A. J. Máquinas e operários: mudança técnica e sindicalismo gráfico (São Paulo e Rio de Janeiro 1858-1912). São Paulo: Annablume: FAPESP, 2000.

VOLOCHÍNOV, V. N. A construção da enunciação e outros ensaios. São Carlos: Pedro \& João Editores, 2013.

Marxismo e filosofia da linguagem: problemas fundamentais do método sociológico na ciência da linguagem. Tradução, notas e glossário de Sheila Grillo e Ekaterina Vólkova Américo. Ensaio introdutório de Sheila Grillo. São Paulo: Editora 34, 2017.

BOENAVIDES, Débora Luciene Porto. Nem no convento, nem no cabaré, na imprensa operária: a ampliação das esferas discursivas da mulher trabalhadora na República Velha. Linguagem em (Dis)curso - LemD, Tubarão, SC, v. 17, n. 3, p. 297-313, set./dez. 2017. 
Recebido em: 08/01/17. Aprovado em: 23/08/17.

Title: Neither in the convent nor in the cabaret, in the working-class press: the enlargement of the discursive spheres of the working woman in the Old Republic

Author: Débora Luciene Porto Boenavides

Abstract: In this article, we investigated how the writing of the working women influenced and reflected the reality of the time in the Brazilian working-class press in the Old Republic (1889-1930). Thereunto, this study, based on the theory of dialogic discourse, firstly opposes two wrong theses that come from elites' imaginary, which, in their representations, they put the working women of that time sometimes in the convent, sometimes in the cabaret, fact that restricted their discursive spheres, as well as the possibilities of their linguistic performances. Then, the article presents the relation between the working women and the working-class press as another history of their language. Despite of all tries to get the voices of the working women to be quiet, through the imposition of discipline, the censorship or the stereotypes, this study shows the texts produced by the working women at the working-class press demonstrate their resistance and point out the confrontations whereby the enlargement of their discursive spheres happened at that time.

Keywords: Dialogism. Press. Woman. Work.

Título: Ni en el convento, ni en el cabaret, en la prensa obrera: la ampliación de las esferas discursivas de la mujer obrera en la República Vieja

Autora: Débora Luciene Porto Boenavides

Resumen: En este artículo se investiga cómo la escrita de la mujer obrera en la prensa obrara brasileña de la República Vieja (1889-1930) influenció y reflexionó la realidad de aquel tiempo. Para ello, el estudio, anclado en la teoría dialógica del discurso, primeramente contrapone dos teses equivocadas provenientes del imaginario de las elites, que en sus representaciones colocaban como lugar de las mujeres obreras de aquél tiempo, en un momento el convento, en otro el cabaret, restringiendo sus esferas discursivas, y con ello, las posibilidades de su actuación lingüística. Después, el artículo presenta la relación de la mujer obrera con la prensa obrera como otra historia de su lenguaje. De esta forma, se demuestra que, a pesar de todos los intentos de callar sus voces, sea por medio de disciplina, de reprocha o de estereotiparlas, los textos de las obreras en la prensa obrera muestran su resistencia y apuntan los enfrentamientos por los cuales ocurrió la ampliación de sus esferas discursivas en aquel tiempo.

Palabras-clave: Dialogismo. Prensa. Mujer. Trabajo.

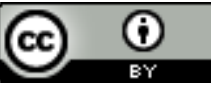

Este texto está licenciado com uma Licença Creative Commons Atribuição 4.0 Internacional. 